\title{
The impact of oxalate ions on barium sulfate
}

\section{crystallization}

Franca Jonest*, Mark I. Ogden*, Tomoko Radomirovic*

$\dagger$ corresponding author

\section{ABSTRACT.}

In this manuscript we investigate the impact of oxalate ions on the crystallization of barium sulfate. The organic anion, oxalate, was found to inhibit both nucleation and growth according to atomic force microscopy measurements and dynamic light scattering data. Raman confocal imaging was used to try and determine how the oxalate interacts with the barium sulfate surface. It was found that barium oxalate is only seen at very high oxalate concentrations. At lower concentrations no direct evidence for the presence of oxalate was observed, however, the most probable mode of action for oxalate is via adsorption onto the barium sulfate surface including into key kink or step sites, impacting growth.

*, Curtin University,

GPO Box U1987, Perth WA 6845 Australia.

Phone: +61892667677 Fax: +61892664699 email: F.Jones@ curtin.edu.au

This research did not receive any specific grant from funding agencies in the public, commercial, or not-for-profit sectors.

KEYWORDS. B1 Barium compounds; A1 impurities; A1 nucleation; A2 growth from solution. 


\section{INTRODUCTION}

Scale is essentially any unwanted crystallization that occurs in a process and its formation can lead to many undesired consequences such as loss of production, loss of product purity and maintenance issues to name but a few [1-4]. Barium sulfate is a well-known scale compound usually encountered during the production of oil from off-shore rigs [1-4]. It is also a relatively simple crystallization system that can be used as a model system. We have used barium sulfate in the past as a model system to investigate the impact of functional group [5], lattice matching [6] and charge effects [7]. Although there is a vast amount of previous literature describing the effect of various organics on the precipitation of barium sulfate (for example [8-10]), there are still many fundamental questions to be answered in this area before the effect of additives can be predicted and their rational design for specific systems can be accomplished.

Scale may be caused by either crystallization promotion or by other crystallization mechanisms, the most important of which is heterogenous nucleation. While crystallization promotion has been observed for calcium carbonate in the presence of polyaspartic molecules [11] and also for barium sulfate in the presence of aspartic acid [12], and the alkali metals [13-15], it is not common to see organic anions behave as crystallization promoters. In the case of aspartic acid, it has been suggested that the mode of action was to weakly complex the barium ion so that it was partially de-solvated, aiding the incorporation of the barium ion into the lattice structure. This is supported by the finding that barium ion de-solvation is a rate-determining step in barium sulfate crystallization $[12,16]$. AFM studies further corroborate this method of action by showing that non-stoichiometric composition in favour of barium ions (i.e. $\left.\mathrm{Ba}^{2+} / \mathrm{SO}_{4}{ }^{2-}>1\right)$ results in faster growth rates for the (001) face [14].

There is a large amount of literature on the impact of organic impurity effects [17, 18]. As previously stated, organics can have variable impacts depending on the functional group present, the charge and, to a lesser extent, the ability to hydrogen bond [19] or the stereochemistry [20]. Organic anions tend to be 
inhibitors of nucleation and/or growth although some can promote crystallization [11, 12]. A comparison to oxalate (the molecule being studied here) is ethylenediaminetetraacetic acid (EDTA) [21]. EDTA was shown to inhibit homogenous nucleation and adsorb preferentially onto the (011) and (100) faces of barium sulfate. It should be stressed that EDTA was found to interact with the barium sulfate surfaces despite EDTA being able to complex $\mathrm{Ba}^{2+}$ in solution, thus, the impact of EDTA was not simply that of a chelator. Thus, in examining the impact of oxalate it is wise not to assume that the main impact will be one of complexation with $\mathrm{Ba}^{2+}$ ions, thereby affecting the supersaturation. Oxalate has also recently been investigated for its impact on calcium carbonate crystallization where it was found that dissolution of the calcite released $\mathrm{Ca}^{2+}$ ions into solution and allowed calcium oxalate monohydrate to form on its surface [22]. This is despite the low solubility of calcite in water, pKsp $\sim 8.32$ [23]. The solubility of the calcium oxalates are, however, of the same order (mono to trihydrate have pKsp $8.69-8.28,[24])$.

The aim of the work, described herein, was to investigate the impact of oxalate ions on barium sulfate crystallization, determine whether complexation was significant or not, determine whether the mechanism of oxalate interaction is similar or dissimilar to EDTA and whether dissolution of barium ions into solution subsequently forming barium oxalate on the surface is a common mechanism or whether this is particular to calcite. Once again the solubility of barium sulfate is rather low $(\mathrm{pKsp}=$ 9.97 [23]) with the solubility of barium oxalate varying from pKsp $7.64-6.92$ depending on whether the anhydrous or dihydrate form is considered $[25,26]$. In this particular case, the oxalate salts do not have solubilities of the same order as the starting material and would not be expected to form under these conditions. In addition, the impact of the oxalate ion on overall de-supersaturation rate, morphology, homogenous nucleation and growth (as determined by AFM on the barite (001) face) was determined. 


\section{EXPERIMENTAL}

The materials used in this study were AR grade, from Ajax Chemicals or BDH and were dissolved to the required concentrations using ultrapure $(>18 \mathrm{M} \Omega \mathrm{cm}$ resistivity) water. Filtered water $(0.2 \mu \mathrm{m})$, having a resistivity of $\geq 18 \mathrm{M} \Omega \mathrm{cm}$, was used throughout. Sodium sulfite (AR grade), was prepared daily at a concentration of $1000 \mathrm{ppm}$ in water as required. Sodium oxalate was AR grade and made up to 1000 ppm stock solution as required. All additives were added to the barium chloride solution prior to sulfate being added to commence the crystallization reaction at the desired concentration.

\subsection{Conductivity}

Unseeded, de-supersaturation curves were conducted using a cell kept at $25^{\circ} \mathrm{C}$ by a water bath and monitored using conductivity (WTW LF 197 Conductivity meter). An overhead stirrer (150 rpm) was used to keep the solids in suspension. The method of barite precipitation consisted of equilibrating 0.249 $\mathrm{mM} \mathrm{BaCl} 2$ and adding $1 \mathrm{~mol}$ equivalent of $\mathrm{Na}_{2} \mathrm{SO}_{4}$ solution to initiate crystallization as described in a previous publication [27]. The total volume for all experiments was $201 \mathrm{~mL}$. The graph of conductivity versus time was used to calculate $\mathrm{k}_{\mathrm{obs}}$ (observed de-supersaturation rate) by fitting the linear region of the de-supersaturation curve. The $\mathrm{pH}$ for all experiments was 6.0 except where specified. The desupersaturation rate was found to have an error of $\sim 10 \%$.

The supersaturation calculated in this manuscript uses the PHREEQC program [23] to calculate the ion activity product, and then this is used to determine the supersaturation S such that:

$$
S=\sqrt{ }\left(\mathrm{IAP} / \mathrm{K}_{\mathrm{sp}}\right)
$$

which is a more accurate measure of the free ions in solution and of the supersaturation than the conventional $\mathrm{S}=\mathrm{c} / \mathrm{c}_{\mathrm{o}}$ (where $\mathrm{c}$ is the concentration of the ion and $\mathrm{c}_{\mathrm{o}}$ is the equilibrium solubility concentration). The square root has been introduced so that comparisons to $S=c / c_{o}$ data is easier. The rate is also normalized according to:

Normalised rate $=\mathrm{k} / \mathrm{k}_{0}$ 
where $\mathrm{k}_{0}$ is the de-supersaturation rate (in the linear region of the curve) for the control run (absence of impurity) and $\mathrm{k}$ is the de-supersaturation rate for the experiment with impurity present.

The solubility product of barium oxalate is above the solubility product of barium sulfate thus, only barium sulfate should crystallize $[26,28]$. However, if the barium ion (present at $\sim 0.25 \mathrm{mM}$ for most experiments) has not reacted with the sulfate ion, this will be at saturation at a concentration of $0.09 \mathrm{mM}$ oxalate if the lower solubility of barium oxalate is assumed. Thus, only above $\sim 0.1 \mathrm{mM}$ oxalate ions could one get possible crystallization of the barium oxalate salt as opposed to barium sulfate (if the value of the barium oxalate $\mathrm{K}_{\mathrm{sp}}$ is taken as $2.3 \times 10^{-8}$, [26]).

\subsection{Light Scattering measurements}

Absorbance was measured using a UV-Vis instrument (GCB) operated at $900 \mathrm{~nm}$ wavelength using a quartz flow cell. When absorbance by the solution and solids is low, this is equivalent to measuring the turbidity (or light scattered) of a system [29]. The induction time is defined as the time prior to the turbidity exceeding background levels and is related to the inverse of nucleation rate for that system [30]. For the barite precipitation experiments, the barium chloride concentration, sodium sulfate concentrations and temperature were all equivalent to those used in the conductivity experiments. The flow rate through the cell was $67 \mathrm{~mL} / \mathrm{min}$ and this was achieved using a Masterflex ${ }^{\circledR}$ peristaltic pump and Tygon ${ }^{\circledR}$ tubing.

\subsection{Morphology and Scanning Electron Microscopy (SEM)}

Morphology experiments were conducted in $25 \mathrm{~mL}$ glass vials. Glass cover slips, cleaned with ethanol and then water, were dried prior to adding to the glass vial. Water (20 mL) and barium chloride (to the desired concentration) was added before equilibration to room temperature after which a sodium sulfate solution (equimolar amounts of $\mathrm{Ba}^{2+}$ and $\mathrm{SO}_{4}{ }^{2-}$ ) was added to commence the crystallization reaction. The total volume was $20.1 \mathrm{~mL}$ for all experiments, the $\mathrm{pH} 6$ and the inorganic impurity added prior to sulfate addition as per the conductivity experiments. The glass cover slips were collected and 
dried using an absorbent tissue to remove excess solution before placing onto a carbon coated SEM stub. Carbon paint was applied to the edges of the glass cover slip to minimize charging effects.

Solids from conductivity runs were collected by filtration onto $0.22 \mu \mathrm{m}$ membranes and this membrane can be seen in the background of the SEM image as a porous structure. After washing and drying in a desiccator, a portion of the filter paper was placed onto carbon-coated stubs and stored in a desiccator. The samples were gold sputtered prior to viewing using a Philips XL30 SEM or a Zeiss Evo SEM at $15 \mathrm{kV}$.

\subsection{Atomic Force Microscopy (AFM)}

AFM experiments were performed on a PicoPlus using a standard silicon nitride cantilever with a flow through cell attachment. The same procedure was used for all samples. A freshly cleaved barium sulfate mineralogical sample was fixed to a metallic stub and the flow cell was flushed with filtered (Gelman $0.2 \mu \mathrm{m}$ Supor $^{\circledR}$ membrane filters) ultrapure water (resistivity $>18 \mathrm{M} \Omega \mathrm{cm}$ ) using a precision dual syringe pump run at $0.2 \mathrm{~mL} / \mathrm{min}$. One syringe then had the water replaced with barium chloride solution $(0.1 \mathrm{mM})$ and the other with sodium sulfate solution $(0.1 \mathrm{mM})$. This was then flushed through the cell at a rate of $0.2 \mathrm{~mL} / \mathrm{min}$ as per the water. Finally, the barium chloride solution was replaced with a solution containing barium chloride plus the impurity of interest at a known concentration and the sodium sulfate solution was topped up as necessary. This was then flushed through the cell at a rate of $0.2 \mathrm{~mL} / \mathrm{min}$ as per the water and pure barium sulfate run. In this way, the rate of growth of the original barium sulfate could be measured and the difference to when impurity was added could be gauged.

\subsection{Confocal Raman Spectroscopy}

Optical images and confocal Raman spectra were collected using the WITec alpha 300SAR, utilising a frequency-doubled NdYAG laser of wavelength $532 \mathrm{~nm}$ and of $50 \mathrm{~mW}$ power. Each Raman spectrum collected consists of 10 accumulations at an integration time of 0.05 seconds and a grating of $600 \mathrm{~g} / \mathrm{mm}$. Analysis was performed using the WITec Project FOUR software. The Raman mapping was performed 
by focussing onto the sample surface and taking an optical image. The scan area was defined using the square scan area tool (typically $10-20 \mu \mathrm{m}$ ). The pixels in the $\mathrm{x}$ and $\mathrm{y}$ direction were set at $\geq 5 \mathrm{x}$ the scan area; thus for a $10 \times 10 \mu \mathrm{m}$ scan the image is a $\geq 50 \times 50$ pixel image. The dimension of the laser spot at the sample is $\sim 300-350 \mathrm{~nm}$ in $\mathrm{x}-\mathrm{y}$ and $\sim 730 \mathrm{~nm}$ in $\mathrm{z}$. Generally, a monolayer of a substance would be difficult to image and detect because the intensity of the Raman shifted light depends on many different factors; for example, scattering efficiency and topology of the sample. However, it was decided to attempt to do so nonetheless.

The samples were prepared by cleaving a mineralogical sample of barium sulfate and placing it into a clean glass vial after which, ultra pure water $(20 \mathrm{~mL})$ was added. Barium chloride at the desired concentration was added after equilibration of the sample to room temperature and finally equimolar sodium oxalate was added at the desired concentration. After 3 days the crystal was removed, gently placed in ultrapure water to remove excess salts and dried using tissue paper to adsorb residual moisture. The dried sample was then placed onto a microscope slide for viewing under the confocal Raman optical microscope.

\subsection{Complexation}

Barium oxalate complexation was simulated using HySS2 software, with the following constants:

$$
\begin{array}{lrl}
\mathrm{Ox}^{2-}+\mathrm{H}^{+}=\mathrm{OxH}^{-} & \log \mathrm{K}=1.252^{*} \\
\mathrm{OxH}^{-}+2 \mathrm{H}^{+}=\mathrm{OxH}_{2} & \log \mathrm{K}=4.266^{*} \\
\mathrm{Ox}^{2-}+\mathrm{Ba}^{2+}=\mathrm{OxBa} & \log \mathrm{K}=2.33^{\#} \\
2 \mathrm{OxBa}^{2-\mathrm{Ox}^{-}}=\mathrm{Ox}_{2} \mathrm{Ba}^{2-} & \log \mathrm{K}=1.62^{\#}
\end{array}
$$

Values taken from

* [22]

\# [31] 


\section{RESULTS}

The degree of barium ion paired with oxalate at $0.1 \mathrm{mM}$ (and $\mathrm{Ba}$ ion concentration at $0.25 \mathrm{mM}$ ) was found to be $<5 \%$ (see supplementary information, SFig 1).

\subsection{Morphology and Conductivity}

The effect of oxalate ions on the morphology of the resultant barium sulfate is best summarized by the images seen in Figure 1. The presence of oxalate ions decreased the aspect ratio of the particles, suggesting that the $c$-axis growth is inhibited relative to the other faces.
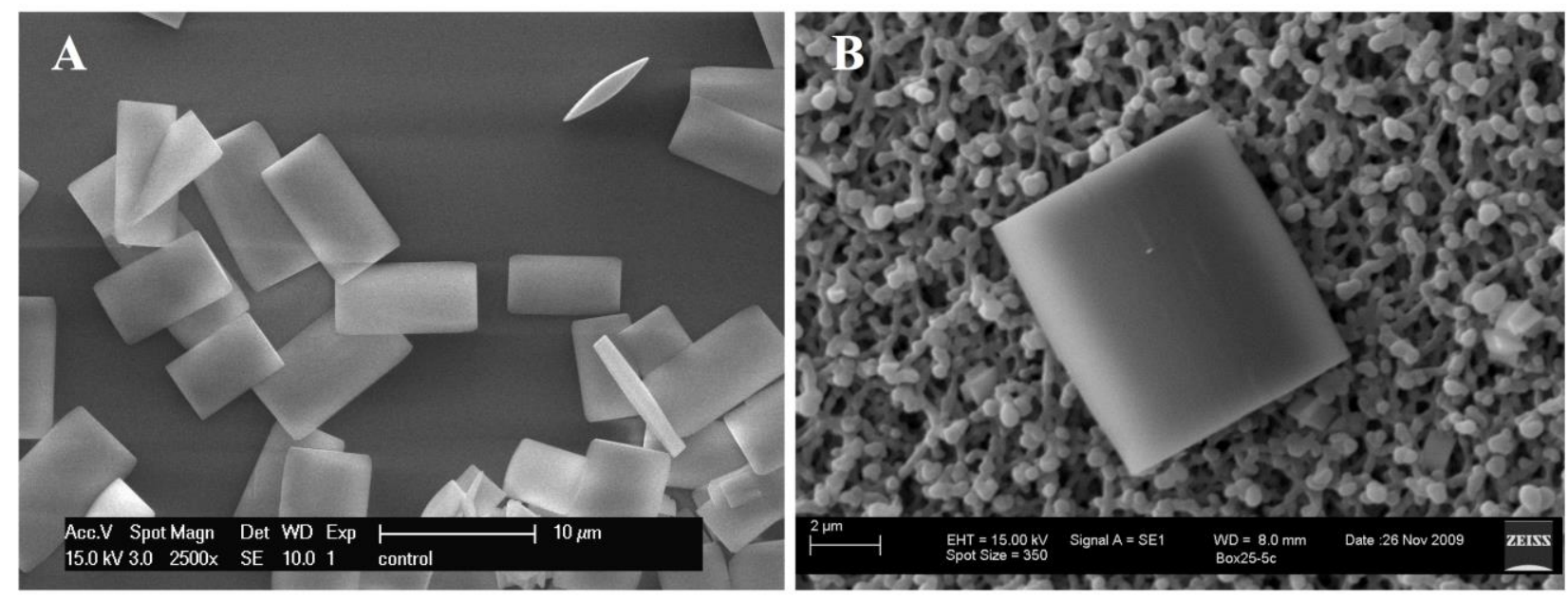

Figure 1. Barium sulfate formed in the presence of A) control (barium sulfate only, $\mathrm{S}=18.8$ ). B) sodium oxalate (0.075 mM) [Double column]

The presence of oxalate during barium sulfate crystallization at lower supersaturation (Figure 2) results in the aspect ratio being closer to 1 for the resultant particles. These particles are similar to the control particles but the particles formed in the presence of oxalate show many protrusions and complex crystal growths. This could be the result of inhibition on the surface of the (001) face leading to growth being forced onto other faces resulting in polycrystalline growth. One possible reason for the different behavior at different crystallization driving forces is that oxalate complexation has impacted the supersaturation of the system. 

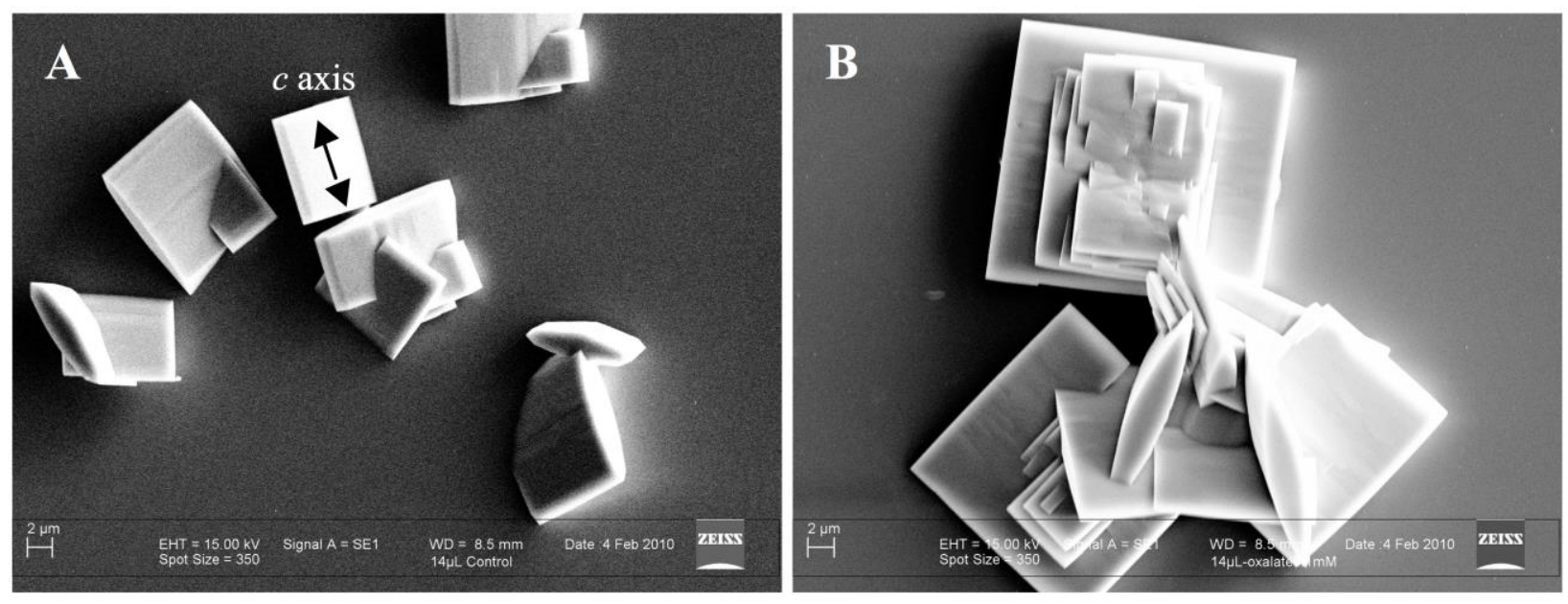

Figure 2. SEM images of barium sulfate particles formed at $S=7$ and A) 0 B) $0.1 \mathrm{mM}$ oxalate ions [Double column]

What can be concluded is that the impact on the growth rate of the (001) face of barium sulfate is more affected by oxalate ions at $\mathrm{S}=18.8$ than $\mathrm{S}=7$. This can be understood in terms of the relationship of growth rate of a face with respect to supersaturation. As shown in SFigure 2 (supplementary section) even a small degree of Ba-oxalate complexation could have a greater impact on the growth rate of the (001) face of barite at $\mathrm{S}=18.8$ than at $\mathrm{S}=7$ if the growth rate of the face is not linearly related to supersaturated.

In the presence of oxalate ions the de-supersaturation rate of an initially $\mathrm{S}=18.8$ barium sulfate solution (Figure 3) decreased except when sodium oxalate was present at $0.11 \mathrm{mM}$, where the desupersaturation rate appears to increase slightly before decreasing once more. At concentrations $>0.08$ $\mathrm{mM}$ this could be because barium oxalate also crystallizes but no evidence, in the microscopy images, for this was observed (see supplementary section, SFigure 3). 


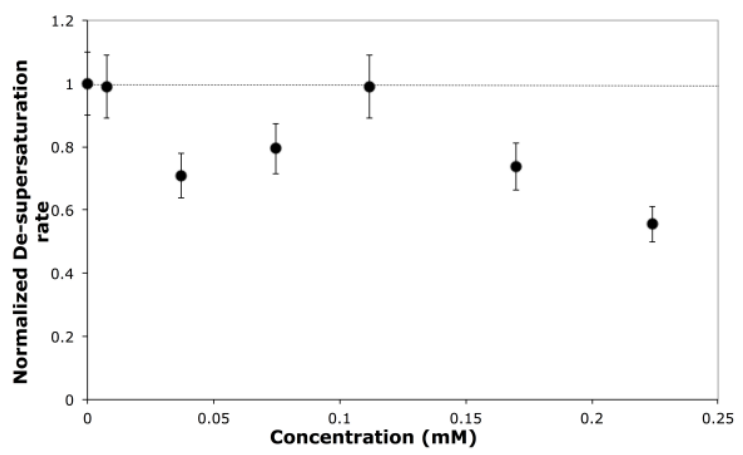

Figure 3. Normalised de-supersaturation rates for barium sulfate crystallized in the presence of oxalate ions [Single column]

\subsection{Turbidity and nucleation impacts}

Turbidimetric data gives information on the induction time, which in turn gives information on the nucleation rates due to the inverse relationship between nucleation rate and induction time [30]. It is observed that the absorbance of the barium sulfate crystallization solution is increasing above background levels at longer and longer times with increasing concentration of oxalate ions (Figure 4). This means increasing induction times of barium sulfate crystallization as the concentration of oxalate increases, thus nucleation rate is decreasing. In this case the effect of oxalate ions is to inhibit homogenous nucleation, even when the concentration of oxalate was presumably above the solubility limit of barium oxalate. In addition, this lowering of the nucleation rate without a lowering of the driving force (since $\mathrm{S}$ is not dramatically changed through complexation) means that the surface free energy of the nuclei has been increased.



Figure 4. Turbidity curves for barium sulfate precipitation in the presence of varying oxalate ion $(0 \mathrm{mM}-$ black, $0.07 \mathrm{mM}$ - black hashed, $0.22 \mathrm{mM}$ - grey, $0.37 \mathrm{mM}$ - grey hashed) [Single column] 


\section{$3.3 \quad A F M$}

The AFM of barium sulfate growth on the (001) face in the presence and absence of this inhibitor confirms some of the mechanistic information already obtained. Figure 5 shows some snapshot images during the in-situ growth of the (001) face of barium sulfate in the presence of oxalate ions. A schematic of the normal growth sector shape and the corresponding growth directions for pure barium sulfate on the $(001)$ is shown in Figure 5a and b. Since the $<100>$ is the slowest growing direction of the growth sector, this direction was chosen to reflect the impact of the various impurities on the growth rate.
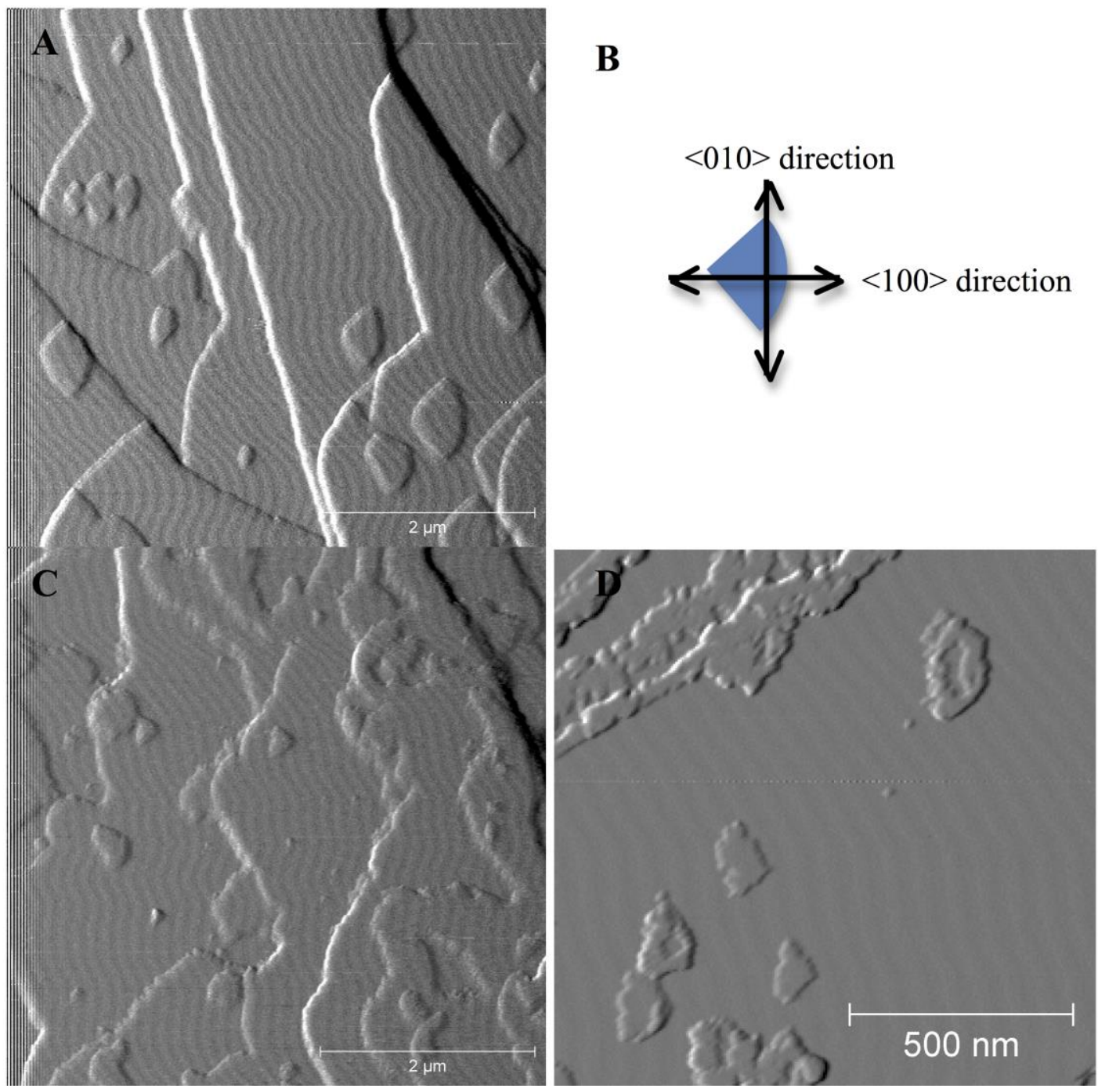

Figure 5. $5 \times 5 \mu \mathrm{m}$ AFM in-situ images (deflection mode) of the (001) growth at $\mathrm{S}=5$ in the presence of A) $0 \mathrm{mM}$ impurity (control) B) schematic showing the growth island and the directions associated with the growth island, C) 0.066 $\mathrm{mM}$ oxalate D) $0.066 \mathrm{mM}$ oxalate at higher magnification and later time period [Double Column] 
The presence of oxalate ions resulted in step pinning of the surface nuclei of barite and these surface nuclei grew sporadically often leaving 'empty' regions (Figure 5d). This indicates that the oxalate ion inhibits the growth of the surface nuclei. The growth rate of the surface nuclei was subsequently measured and shown in Figure 6a. It is clearly observed that the growth of the surface nuclei decreased with increasing oxalate concentration, quickly dropping off to zero. In addition, the number of new surface nuclei (Figure 6b) also decreased overall. Thus, 2D nucleation and growth are inhibited in the presence of oxalate ions. Unlike the case for calcium carbonate, no new surface features indicative of a barium oxalate surface were ever observed. The inhibition observed in the presence of oxalate ions cannot be attributed to complexation. As previously stated only a 5\% difference in barium ion activity can be assumed while the growth rate continues to decrease with increasing oxalate concentration. This, combined with the step pinning observed suggests that the oxalate ion is also interacting with the surface. While the most probable growth sites are the kink and step sites, adsorption onto the terraces of the surface is also expected. Combined with the morphology experiments, this suggests that the main impacts of the oxalate ion is not through complexation but through surface adsorption as per EDTA. The impact on morphology is perhaps not as great as that of EDTA where rice shaped particles were formed but it is clear that complexation cannot sufficiently explain the impacts of oxalate ions.
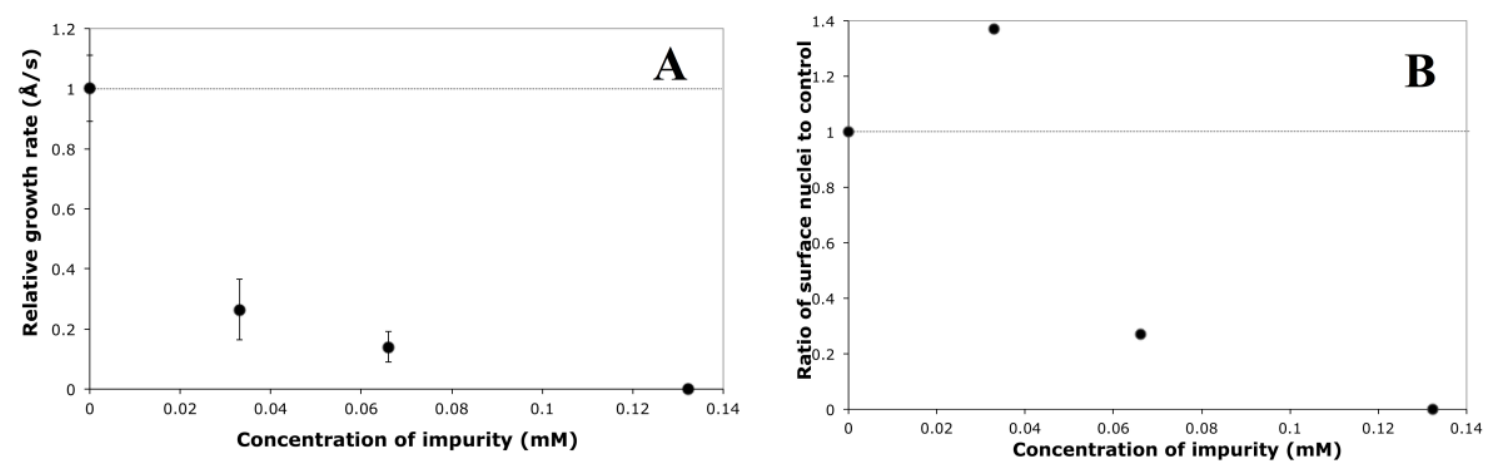

Figure 6. (A) Growth rate of barium sulfate in the $\langle 100\rangle$ direction relative to the control and (B) ratio of surface nuclei compared to control (on $5 \times 5 \mu \mathrm{m}$ scan) [Double Column] 


\subsection{Oxalate ion interaction by Confocal Raman Spectroscopy}

In order to be able to differentiate the barium sulfate from oxalate in the Raman, scans were taken of each (at $100 \mathrm{mM}$ oxalate ion) and are shown in the supplementary section (SFigure 4). Areas were then chosen on the crystal exposed to barium, sulfate and oxalate ions to image and for concentrations of barium oxalate up to $0.2 \mathrm{mM}$ no evidence of barium oxalate was found (supporting the AFM results that also showed no new barium oxalate features) and only barium sulfate spectra were recorded. For concentrations of barium oxalate at $100 \mathrm{mM}$ images such as those shown below (Figure 7) were obtained.
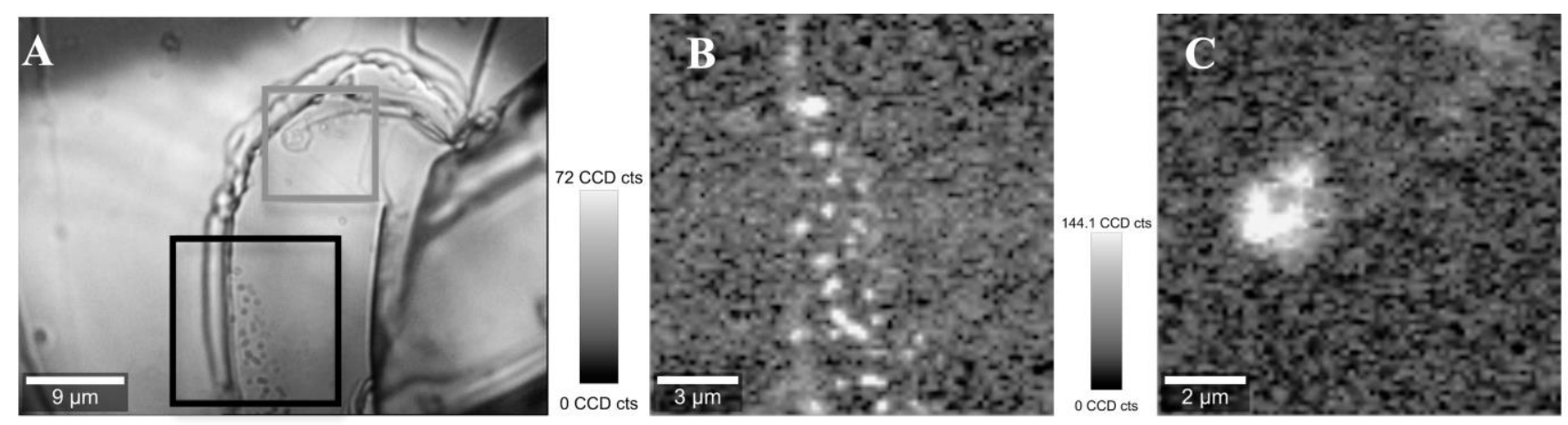

Figure 7. (A) Optical image of barium sulfate after drying in the presence of $100 \mathrm{mM} \mathrm{BaC}_{2} \mathrm{O}_{4}$, (B) Raman map of $1480 \mathrm{~cm}^{-1}$ band intensity (oxalate diagnostic) for area shown by black box, (C) Raman map of $1480 \mathrm{~cm}^{-1}$ band intensity (oxalate diagnostic) for area shown by grey box [Double Column]

While no oxalate spectrum could be recorded at lower concentrations, this does not mean oxalate ions do not adsorb onto the surface, since morphological and other effects were observed. It only suggests that the amount of oxalate ions adsorbed is low and below the detection limit of this technique. While oxalate ions impact nucleation probably by increasing the surface free energy, the impact on crystal growth is most probably caused by adsorbing onto the critical kink sites. At higher concentrations, barium oxalate is clearly seen to form (see above and supplementary information, SFigure 4). However, even at these high concentrations, no distinct accumulation of oxalate at the steps (where kink sites would presumably be located) can be observed. We can, thus, rule out the formation of a distinct barium 
oxalate layer as being the cause of the inhibition. In this case, as expected the solubility of the barium oxalates are too high to be observed in this system.

\section{SUMMARY}

In conclusion, the oxalate ion generally inhibited barium sulfate precipitation. The overall desupersaturation rate decreases with increasing oxalate ion concentration. In addition, homogenous nucleation of barite appears to be inhibited by the presence of oxalate ions as determined from turbidimetric results. Increasing induction times result with increasing oxalate concentration. Finally, both 2D nucleation and growth of barium sulfate appear to be inhibited when oxalate ions are present as determined by AFM analysis. Like EDTA, these impacts cannot be attributed solely or significantly to complexation and changes in the barium ion activity. Like EDTA, the impact of oxalate ions appears to be due to surface interactions.

The AFM analysis of this impurity on barium sulfate showed that overall, oxalate inhibited 2D growth via step pinning. This suggests adsorption of the oxalate ion on the surface, though not observable through the confocal Raman investigation. Oxalate was observed to significantly inhibit step growth of barium sulfate reducing it to close to zero at a concentration of $\sim 0.07 \mathrm{mM}$ oxalate. The presence of oxalate did not lead to significant barium oxalate formation either in the morphology or AFM studies even when the system was supersaturated with respect to barium oxalate. This can be understood in terms of the solubilities of the barium sulfate versus the barium oxalate phases.

Only at high oxalate concentrations was barium oxalate observed (in the confocal study). This suggests that the barium ion reacts preferentially with the sulfate ions, presumably due to the higher driving force (supersaturation). This suggests that metal oxalate formation is not a general mechanism of interaction for oxalate ions but is specific and dependent on the solubility of the system under investigation. 
We would like to acknowledge Dr. Thomas Becker for the use of the AFM facilities and the confocal instrument (Curtin Institute of Functional Materials and Interfaces, Dept. of Chemistry, Curtin University) and the John de Laeter Centre for use of the SEM, TEM, and XRD facilities. We thank the Museum of Western Australia (A. Bevan) for the mineralogical barium sulfate sample used in the AFM study - the sample origin of which was Westmorland UK.

Supplementary Information: further morphorphy results, Barium ion complexation simulation, confocal image and Raman spectra used to differentiate barium oxalate and barium sulfate.

6. REFERENCES.

[1] M. S. Antonious, Phosphorous, Sulfur, Silicon Relat. Elem., 1996, 112, 235-245.

[2] R. H. Hausler, Oil and Gas Journal, 1978, Sept 18, 146-154.

[3] A. Quddus and I. Allam, Desalination, 2000, 127, 219-224.

[4] K. S. Sorbie and N. Laing, in 6th International Symposium on oilfied Scale, Society of Petroleum Engineers Inc, Aberdeen Scottland, 2004, p. SPE 87470.

[5] F. Jones, M. Mocerino, M. I. Ogden, A. Oliviera and G. M. Parkinson, Crystal Growth \& Design, 2005, 5, 2336-2343.

[6] F. Jones, W. R. Richmond and A. L. Rohl, J. Phys. Chem. B., 2006, 110, 7414-7424.

[7] F. Jones, J. Clegg, A. Oliviera, A. L. Rohl, M. I. Ogden, G. M. Parkinson, A. M. Fogg and M. M. Reyhani, CrystEngComm, 2001, 40, 1-3.

[8] E. Barouda, K. D. Demadis, S. R. Freeman, F. Jones and M. I. Ogden, Crystal Growth \& Design, 2007, 7, 321-327.

[9] P. V. Coveney, R. J. Davey, J. L. W. Griffin, Y. He, J. D. Hamlin, S. Stackhouse and A. Whiting, J. Am. Chem. Soc., 2000, 122, 11557-11558.

[10] C. Garcia, G. Courbin, F. Ropital and C. Fiaud, Electrochimica Acta, 2001, 46, 973-985.

[11] S. Elhadj, E. A. Salter, A. Wierzbicki, J. J. De Yoreo, N. Han and P. M. Dove, Crystal Growth \& Design, 2006, 6, 197-201.

[12] S. Piana, F. Jones and J. D. Gale, CrystEngComm, 2007, 9, 1187 - 1191.

[13] U. Becker, P. Risthaus, D. Bosbach and A. Putnis, Molecular Simulation 2002, 28, 607-632.

[14] M. Kowacz, C. V. Putnis and A. Putnis, Geochimica et Cosmochimica Acta, 2007, 71, 51685179.

[15] P. Risthaus, D. Bosbach, U. Becker and A. Putnis, Colloids and Surfaces. A., 2001, 191, 201214.

[16] S. Piana, F. Jones and J. D. Gale, J. Am. Chem. Soc., 2006, 128(41), 13568-13574.

[17] F. Jones and M. I. Ogden, CrystEngComm, 2010, 12, 1016-1023.

[18] R.-Q. Song and H. Cölfen, CrystEngComm, 2011, 13, 1249-1276.

[19] F. Jones, A. Oliviera, A. L. Rohl, M. I. Ogden and G. M. Parkinson, CrystEngComm, 2006, 8, 869-876.

[20] A. L. Rohl, D. H. Gay, R. J. Davey and C. R. A. Catlow, J. Am. Chem Soc., 1996, 118, $642-648$.

[21] F. Jones, P. Jones, M. I. Ogden, W. R. Richmond, A. L. Rohl and M. Saunders, Journal of Colloid and Interface Science, 2007, 316, 553-561. 
[22] A. Burgos-Cara, C. V. Putnis, M. Ortega-Huetas and E. Ruiz-Agudo, CrystEngComm, 2017, 19, 3420-3429

[23] D. L. Parkhurst and C. A. Appelo, Users guide to PHREEQC (version 2) - a computer program for speciation, batch reaction, one dimensional transport, and inverse geochemical calculations, U.S. Geological Survey Water-Resources Investigation Report, 1999.

[24] L. Brečević, D. Škrtić and J. Garside, J. Cryst. Growth, 1986, 74, 399-408.

[25] H. Lohninger, http://www.vias.org/genchem/solubility product table.html, accessed Jan 29, 2018.

[26] O. Seely, Selected solubilty products and formation constants at $25^{\circ} \mathrm{C}$, Accessed 11 th September, 2017.

[27] F. Jones, A. Oliviera, G. M. Parkinson, A. L. Rohl, A. Stanley and T. Upson, Journal of Crystal Growth, 2004, 270, 593-603.

[28] R. W. Money and C. W. Davies, Journal of the Chemical Society (Resumed), 1938, article 398, 2098-2100.

[29] T. Radomirovic, P. Smith and F. Jones, Int. J. Mineral Processing, 2013, 118, 59-64.

[30] J. W. Mullin, Crystallization, Butterworth-Heinemann Publishers Ltd, London, 1993.

[31] P. May and K. Murray, Joint Expert Speciation System (JESS), online data base of constants found at http://jess.murdoch.edu.au/jess_home.htm, accessed $27^{\text {th }}$ July 2017. 